\title{
Design of simulation-based medical education and advantages and disadvantages of in situ simulation versus off-site simulation
}

\author{
Jette Led Sørensen ${ }^{1 *}$ D, Doris Østergaard ${ }^{2}$, Vicki LeBlanc ${ }^{3,4}$, Bent Ottesen ${ }^{1}$, Lars Konge ${ }^{5}$, Peter Dieckmann ${ }^{2}$
} and Cees Van der Vleuten ${ }^{6}$

\begin{abstract}
Background: Simulation-based medical education (SBME) has traditionally been conducted as off-site simulation in simulation centres. Some hospital departments also provide off-site simulation using in-house training room(s) set up for simulation away from the clinical setting, and these activities are called in-house training. In-house training facilities can be part of hospital departments and resemble to some extent simulation centres but often have less technical equipment. In situ simulation, introduced over the past decade, mainly comprises of team-based activities and occurs in patient care units with healthcare professionals in their own working environment. Thus, this intentional blend of simulation and real working environments means that in situ simulation brings simulation to the real working environment and provides training where people work. In situ simulation can be either announced or unannounced, the latter also known as a drill. This article presents and discusses the design of SBME and the advantage and disadvantage of the different simulation settings, such as training in simulationcentres, in-house simulations in hospital departments, announced or unannounced in situ simulations.
\end{abstract}

Discussion: Non-randomised studies argue that in situ simulation is more effective for educational purposes than other types of simulation settings. Conversely, the few comparison studies that exist, either randomised or retrospective, show that choice of setting does not seem to influence individual or team learning. However, hospital department-based simulations, such as in-house simulation and in situ simulation, lead to a gain in organisational learning. To our knowledge no studies have compared announced and unannounced in situ simulation. The literature suggests some improved organisational learning from unannounced in situ simulation; however, unannounced in situ simulation was also found to be challenging to plan and conduct, and more stressful among participants. The importance of setting, context and fidelity are discussed.

Summary: Based on the current limited research we suggest that choice of setting for simulations does not seem to influence individual and team learning. Department-based local simulation, such as simulation in-house and especially in situ simulation, leads to gains in organisational learning. The overall objectives of simulation-based education and factors such as feasibility can help determine choice of simulation setting.

Keywords: Simulation-based medical education, In situ simulation, Inter-professional, Curriculum, Fidelity, Context, Cross-training

\footnotetext{
* Correspondence: Jette.led.soerensen@regionh.dk

${ }^{1}$ Juliane Marie Centre for Children, Women and Reproduction, Rigshospitalet,

University of Copenhagen, 2100 Copenhagen, Denmark

Full list of author information is available at the end of the article
} 


\section{Background}

Simulation-based medical education (SBME) is increasingly recommended, as an educational strategy and for improving patient safety $[1-10]$. One review concluded that future research should clarify the mechanisms behind effective simulation-based education by asking: "What works, for whom, in what contexts?" [6]. One poorly addressed issue in SBME original research studies and reviews is the choice of context and setting for SBME.

Overall, SBME is a complex educational intervention. SBME was defined by Issenberg et al. as: "In broad, simple terms a simulation is a person, device, or set of conditions which attempts to present education and evaluation problems authentically. The student or trainee is required to respond to the problems as he or she would under natural circumstances" [2]. Simulation techniques and devices can comprise, for example of high-tech virtual reality simulators, full-scale mannequins, plastic models, instructed or standardised patients, animal or animal products, human cadavers, or screen-based simulators. These simulation modalities can be applied in all kinds of simulation settings, and SBME can be applied in various settings target individuals, teams or both, but also aim for organisational learning, such as e.g. practical changes in equipment, guidelines or the physical clinical environment.

Learning in context is a highly discussed topic in medical education $[2,11]$. Context can be understood as the circumstances in which a task is undertaken [12]. Various studies indicate that learning can be better applied or recalled when the context and the learning environment resemble the retrieval environment [11, 13, 14]. Medical educators and empirical findings, however, increasingly question this assumption [15-17]. In the following sections we discuss the SBME setting, the design of simulation and the concept of learning in context.

The planning and conduction of SBME may be influenced by the level of fidelity. Fidelity refers to the degree of faithfulness that exists between two entities, and these entities are fundamental for the transfer of SBME and performance in the clinical setting [16]. The notion behind this idea concerning the fidelity of simulation is rooted in the traditional assumption that the closer the learning context resembles the context of practice, the better the learning [14] and is a premise that is discussed below in detail. Fidelity is understood as important in SBME and may improve the effectiveness of a simulation, thereby preparing participants to perform clinically [16]. In the 1990s, the term fidelity was defined in various ways in the flight simulation literature [18], which served as the basis for its later introduction into the medical education literature. The medical educational literature adapted a definition of fidelity divided into two parts [17, 19]: 1) physical or engineering fidelity, which is the degree to which the simulators duplicate the appearance of the real system, and this also covers environmental fidelity; and 2) psychological fidelity, which is the degree to which the simulation participants perceive the simulation as an authentic surrogate for the task being trained. These aspects of fidelity are interrelated, and different modalities of simulation can be combined to increase both physical and psychological fidelity. The complex term, fidelity is discussed in this article with a focus on physical fidelity, i.e. the resemblance of the simulation setting and context to the real setting and context.

\section{Types of simulation settings}

SBME has largely been conducted in an off-site simulation (OSS) setting in simulation centres, which range widely from publically financed simulation centres at hospitals and universities to simulation centres that are detached facilities funded by sponsors and user payment. Some hospital departments also provide OSS as inhouse training room(s) specifically set up for simulation training away from the clinical setting but within the hospital department [20-23]. In-house training facilities can be part of hospital departments and resemble to some extent simulation centres but often have fewer technical devices, e.g. permanent audio-visual recording equipment. OSS in-house activities require that departments are able to provide simulation equipment and to ensure that simulation instructors are trained well enough to supply professionally and educationally sound simulations.

Introduced over the past 10 years in situ simulation (ISS) mainly comprises team-based activities that occur in the actual patient care units involving actual healthcare team members in their own working environment [24]. Rosen et al. describe ISS as a blend of simulation and real working environments designed to provide training where people actually work [19]. ISS can also focus on individual skills. ISS can be conducted either announced or unannounced $[19,25]$, the latter also termed as a drill [25]. Table 1 presents an overview of the different simulation settings.

This article discusses the advantages and disadvantages of the choice of simulation setting and the design and delivery of SBME, including choice of target groups, objectives and assessment procedures. We will also provide some tips and share the lessons we have learned, especially when introducing ISS. In this article we focus on postgraduate and interprofessional simulation, and it is beyond focus of the article to discuss simulation for medical or other healthcare professional undergraduate students.

\section{Discussion}

All types of SBME require meticulous planning, which is well described and corroborated by several reviews 
Table 1 Various types of physical simulation settings

\begin{tabular}{ll}
$\begin{array}{l}\text { Type of physical simulation } \\
\text { settings }\end{array}$ & Description \\
\hline $\begin{array}{l}\text { Off-site simulation in simulation } \\
\text { centre }\end{array}$ & $\begin{array}{l}\text { Conducted and placed away from the actual patient care unit; simulation-centres range from publically financed } \\
\text { centres at hospitals and universities to simulation centres that are detached facilities funded by sponsors and user } \\
\text { payment }\end{array}$ \\
$\begin{array}{l}\text { Off-site simulation in-house } \\
\text { in department }\end{array}$ & $\begin{array}{l}\text { Conducted in training room(s) specifically set up for simulation training away from the clinical setting, but within } \\
\text { the hospital in-house training facilities can be part of hospital departments and resemble to some extent } \\
\text { simulation centres however often have fewer technical devices, e.g. permanent audio-visual recording } \\
\text { equipment }\end{array}$ \\
$\begin{array}{ll}\text { In situ simulation } \\
\text { In situ simulation announced } \\
\text { In situ simulation unannounced of simulation and real working environments designed to provide training where people actually work, }\end{array}$ & $\begin{array}{l}\text { The staff is informed about the simulation event } \\
\text { The involved staff do not have prior knowledge of the event; Can also be termed as a drill }\end{array}$ \\
\hline
\end{tabular}

$[2,3,8,9]$. To facilitate the discussion about advantages and disadvantages of the choice of simulation setting, Table 2 presents a schematic overview of how simulation settings are potentially related to various components in SBME, which will be discussed in the following. Table 2 is based on various sources and articles, including reviews about ISS $[19,26]$ and literature specifically addressing randomised and retrospective studies that compare differences in simulation settings [20, 23, 27-29]. The authors went through the literature and discussed and compiled Table 2.

Table 2 How various aspects of simulation-based medical education affect the physical simulation setting. Blank spaces indicate that the item has little or no effect; $x$ that the item can have an effect; $x x$ that the item can have a strong effect

\begin{tabular}{|c|c|c|c|c|}
\hline & $\begin{array}{l}\text { Off-site simulation } \\
\text { in simulation centre }\end{array}$ & $\begin{array}{l}\text { Off-site simulation } \\
\text { in-house in department }\end{array}$ & $\begin{array}{l}\text { In situ simulation } \\
\text { announced }\end{array}$ & $\begin{array}{l}\text { In situ simulation } \\
\text { unannounced }\end{array}$ \\
\hline 1.Less risk of cancellation due to heavy patient load & $x x$ & $x x$ & $x$ & \\
\hline $\begin{array}{l}\text { 2.Reported to promote better involvement of all postgraduate } \\
\text { healthcare professionals }\end{array}$ & & $x$ & $x$ & $x$ \\
\hline 3.No risk of staff being called away for clinical work & $x x$ & $x$ & & \\
\hline 4.Does not require travel time; accessibility for staff easier & & $x x$ & $x x$ & $x x$ \\
\hline $\begin{array}{l}\text { 5.Popular and promotes recruitment of postgraduate } \\
\text { healthcare professionals }\end{array}$ & & & $x$ & $x$ \\
\hline 6.Not described as anxiety provoking & $x$ & $x$ & $x$ & \\
\hline 7.May potentially give a greater feeling of safety psychologically & $x$ & & & \\
\hline 8.Enhances individual learning & $x$ & $x$ & $x$ & $x$ \\
\hline 9.Enhances team learning & $x$ & $x x$ & $x x$ & $x x$ \\
\hline 10.More time potentially set aside, especially for debriefing & $x x$ & $x$ & $x$ & \\
\hline $\begin{array}{l}\text { 11.Ideas for organisational changes brought back to the } \\
\text { organisation (latent patient safety issues) }\end{array}$ & & $x$ & $x x$ & $x x$ \\
\hline $\begin{array}{l}\text { 12.No potential risk of safety hazards due to mixing up medical } \\
\text { equipment and utensils }\end{array}$ & $x x$ & $x$ & & \\
\hline $\begin{array}{l}\text { 13. No potential risk of unintentional involvement of patients } \\
\text { and relatives }\end{array}$ & $x x$ & $x x$ & $x$ & \\
\hline $\begin{array}{l}\text { 14. More efficient use of simulation equipment, which can be } \\
\text { shared by many departments, and better facilities to ensure } \\
\text { efficient use of high-tech simulation equipment }\end{array}$ & $x x$ & & & \\
\hline $\begin{array}{l}\text { 15.Potentially more efficient simulations due to development } \\
\text { of simulation curriculum }\end{array}$ & $x x$ & $x$ & $x$ & $x$ \\
\hline $\begin{array}{l}\text { 16. Easier access for technicians if simulation equipment has } \\
\text { technical problems }\end{array}$ & $x x$ & & & \\
\hline $\begin{array}{l}\text { 17.Team-based and low-tech simulation can be cheaper due } \\
\text { to use of local facilities and equipment }\end{array}$ & & $x$ & $x x$ & $x x$ \\
\hline $\begin{array}{l}\text { 18.Potentially more efficient simulations due to better training } \\
\text { of simulation instructors }\end{array}$ & $x x$ & $x$ & $x$ & $x$ \\
\hline
\end{tabular}




\section{Choice of learning objectives}

Selection the simulation setting for SBME must be guided by the learning objectives. Learning objectives and integration of SBME into the overall curriculum are an essential aspect of curriculum design for every type of educational intervention [30]. As a result, scenarios based on well-defined learning objectives are crucial, and simulation activities can only be as good as the educational programme in which they are embedded [1, 3 , 31]. Decades ago, a paper on flight simulation concluded that "The key is the programme, not the hardware" [32], an aspect that Salas et al. also highlight [9]: "Simulators do not make a curriculum, they are merely tools for a curriculum". Objectives must initially be defined clearly, each of which can focus more on individual or teambased activities, such as communication, cooperation and teamwork, but also on cognitive skills like decision making or on technical and clinical topics. Learning objectives can also be organisational. By organisational learning we mean ideas on organisational and practical changes in e.g. equipment, guidelines and the physical clinical environment [33]. A recent international expert group concluded [10] that system probing, which is an organisational approach, is one of five topics that healthcare simulation can address to improve patient safety. System probing is used to identify patient safety problems that can be improved by training or by system changes and it can serve as a needs assessment and to help define learning objectives and educational interventions [10]. A variety of ISS programmes are designed specifically to test organisational practice [19], i.e. to test new rooms or wards in a hospital [34]. This can, however, cause confusion among participants in a simulation due to the multi-level focus on the individual, team and organisational setup, which is why clearly defined objectives are vital. Learning on an organisational level can differ from individual and team learning [19, 22, 27, 33]. For example, organisational learning can involve changes beyond individual behaviour, like changes in equipment in emergency boxes, in procedures for calling staff and in guidelines [22, 24, 25].

\section{Target groups}

SBME can focus on individual skills training for a specific healthcare professional group or on team training for various healthcare professional groups. Inter-professional simulation is on the agenda in many organisations, which is why it is important to acknowledge that it requires substantial planning and that inter-professional planning requires the use of inter-professional curriculum committees [22, 27, 35]. Boet et al. provide ample information on how to create simulations inter-professionally [35]. Simulations must be developed that provide each healthcare professional group with a significant role to play and involve incorporating a variety of objectives for each group. Adopting this kind of more holistic view is also described as helpful in interprofessional postgraduate simulation [35].

\section{There is a difference between training and assessment}

$\mathrm{Be}$ aware of the difference between simulation-based training and simulation-based assessment of simulation participants [30]. In the pre-briefing it is important to tell simulation participants what is expected of them [35]. Assessing participants individually may be relevant and participants who have been tested have been shown to have better retention as a result of what is known as the testing effect [36]. However, some simulation participants may experience that being assessed disrupts the feeling of being in a safe learning environment [37]. Developing a test to be applied in an inter-professional context will, in addition to curriculum development, require the involvement of all the healthcare professional groups that are part of the simulation intervention [38].

Simulation will probably increasingly be used for assessment. In a review Brydges et al. concluded that simulation-based tools may replace work-based assessment of selected procedural skills [7], but McGaghie et al. concluded that less evidence is found on the benefit of SBME in teams as there is still a lack of team-based metrics and standards [4].

With the general move towards more competencybased medical education and workplace-based assessment $[39,40]$, the role of formative assessment and feedback can be expected to increase. This will likely increasingly blur the line between training and assessment, potentially influencing the role of assessment and the attitudes towards assessment among simulation participants.

\section{Planning of unannounced in situ simulation (Table 2, point 1)}

All simulation requires detailed planning, but particularly unannounced ISS requires multifaceted planning and the need for good management support [22, 26, 29, 41]. Wellestablished cooperation between educational planners and the departmental management is required and actively involving representatives from all healthcare professional groups results in better planning of postgraduate interprofessional simulation [21, 22, 26-28, 35, 42]. Still, simulation instructors must be prepared to cancel or postpone scheduled unannounced ISS in the event of heavy patient loads or a shortage of staff $[22,43]$. The average reported rate of cancellation for unannounced ISS is $28-67 \%$ [22, $41,43]$ but the percentage seems to go down as training matures [41]. Unannounced ISS must not pose any risk to real-life patients, which means extra staff must replace staff participating in the unannounced ISS [22]. 


\section{Healthcare professionals prefeences in simulation}

(Table 2, point 2-5)

One idea is to make simulation facilities more accessible for all staff in a multiprofessional organisation, which in several articles are an argument for delivering of simulation as ISS and OSS in-house in departments [19-21, 23, 27, 28].

A retrospective study comparing OSS in a simulationcentre with announced ISS found the same outcome in video ratings of team performance in various simulation settings [29]. However, survey-based data showed that participants favoured ISS, which can be seen as an argument to apply ISS to improve recruitment [29].

In a qualitative study staff informed that they had a preconceived preference for participating in ISS because they believed that ISS better matched reality and assumed that this would affect their ability to involve themselves [28].

Some argue in favour of conducting OSS in a simulation centre where the staff cannot be called away for clinical work. The comparison studies on simulation settings [20, 23, 27-29] do not specifically address this issue.

\section{Some health-care professional experience in situ simula- tion as anxiety provoking (Table 2 , point 6,7 )}

Some individuals who have participated in unannounced ISS describe it as intimidating [25], but this topic is poorly explored in the literature. One study found that approximately one-third of all staff members thought that unannounced ISS was stressful and unpleasant, despite the fact that all staff members beforehand had been told that a number of unannounced ISS would take place within a specific period [22].

Conducting OSS or an announced ISS can potentially ensure a safer learning environment than unannounced ISS, even though simulation in itself is also reported to be perceived as stressful or intimidating [44]. Boet et al. also reported widespread anxiety concerning inter-professional learning as it entails various difficult interactions involving people from a range of professional groups and perceived status [35]. The precise interplay of the many factors impacting how safe simulation participants feel during simulation remains to be explored. This also underlines the importance of training programmes for simulation instructors [45].

Some argue that potential conflicts of interest from preexisting personal relationships between simulation instructors and professional healthcare staff can be avoided when simulation is conducted in a simulation centre [46]. This topic is not in focus in any empiric studies.

Simulation settings do not appear to influence individual and team outcomes (Table 2, point 8-10)

Several non-randomised studies argue that ISS is more effective for learning than OSS because the simulation is conducted in a more authentic environment [24, 41, 47-50]. Little is known about the effect of the physical setting on the practice of simulation [51,52]. To our knowledge, there are only a handful of studies [20, 23, 2729] in the medical domain that use randomised or retrospective studies to compare various simulation settings in terms of outcomes. A randomised trial involving training announced ISS versus OSS in-house tested this hypothesis [27]. The ISS and OSS scenarios were identical and standardised, and the simulation instructors were trained to conduct the simulations in a comparative way in both settings. The ISS participants scored the authenticity of the simulation scenarios significantly higher than the OSS participants, but the comparison of ISS versus OSS in-house did not reveal any significant differences regarding all other variables measured, such as individual knowledge, patient safety attitudes, stress measurements, perceptions of the simulations and video-assessed team performance [27]. The findings showed that the only difference was that ISS had an organisational impact. A subsequent qualitative study confirmed that ISS and OSS participants had similar individual and team learning experiences [28].

Another randomised trial comparing OSS in a simulation centre with OSS in-house training showed that the simulation setting was not of importance for the outcome, as expressed by no difference in the acquisition of knowledge and no differences in completion for basic tasks and teamwork [20, 23].

Some argue that more time is potentially set aside, especially for debriefing in OSS [46]. However this is not addressed in empiric studies. The time-issue in unannounced ISS is clear [22, 41, 43], and less time is maybe therefore spent on debriefing.

To our knowledge there are no studies comparing announced and unannounced ISS. Further studies are also needed that include outcome on long-term retention and patient-based outcomes.

\section{In situ simulation achieves greater learning at the organisational level (Table 2, point 11)}

Simulation can be used to test equipment, new procedures and physical environments. Articles on ISS discuss the value of ISS for identifying latent safety threats in organisations [19, 24, 27, 41, 47, 53]. Testing equipment and procedures can take place in simulation centres, but the literature focuses on ISS. Studies describe how ISS can successfully be used to test the renovation of wards and the construction of new wards [34, 54-57] or to determine how to perform individual procedures [56].

A randomised trial and a subsequent qualitative study confirm that more information on organisational deficiencies comes from ISS participants compared to OSS participants in-house [27, 28]. OSS in-house training is 
described as useful for identifying organisational deficiencies $[21,27,28,58]$, but the ISS setting in particular provides more information than OSS on deficiencies concerning technology and tools $[27,33]$.

In situ simulation and in-house simulation may compromise patient safety (Table 2, point 12-13)

A potential disadvantage of doing simulations that take place outside a simulation centre is that ISS and OSS inhouse can compromise patient safety [59]. For example medication prepared for ISS or OSS in-house can potentially get mixed up with real medication, or equipment used for ISS might be returned without being made ready for use in real clinical situations $[46,59]$. Using labels marked "Simulation only" can be a precaution that can be taken to avoid these problems. ISS will most often involve the use of equipment from the clinical site, thus making it simpler to plan, whereas OSS in-house simulation instructors must organise all relevant equipment. Conducting OSS in-house and ISS requires storage space for equipment, and simulation instructors have to schedule time to organise mannequins and equipment. Faculty planning simulations must also incorporate cleanup procedures and an awareness among simulation instructors of how patient safety can be compromised due to poor planning [59]. ISS can also potentially upset patients [59], but providing useful information for patients and relatives may also result in a positive effect. Signage can help them to recognise the training nature of the activities. If a research approach is taken in this new process, knowledge on the perspective of patients and relatives can be gathered.

\section{Simulation can be used to test facilities in new building facilities}

A more recently applied use of OSS modalities can involve using a mock-up or sandbox technique $[60,61]$ when constructing and testing new facilities. The mock-up technique is a 1:1 construction of a unit or other rooms that allows architects and designers, in cooperation with clinical staff, to test ideas and solutions [60]. The sandbox technique allows staff to practice new care delivery in new buildings [61]. It is important to apply these simulation methods in the early phases of planning and decision making when building new wards and hospitals. Recent literature on the design of new hospitals stresses the lack of integration between physical learning spaces and underlying teaching strategies [62].

\section{Integration of simulation into the educational strategy of departments}

Simulation is expected in the future to be an increasingly recommended educational strategy for all healthcare professionals, just as an increase in inter-professional simulation programmes is expected [35]. Practicing teamwork integrated with simulation-based skills training that encompasses a clinical approach is preferable and has been shown to be associated with significant improvements [37, 58, 63, 64].

One idea is to make simulation facilities more accessible for staff and to integrate simulation into the educational strategy of departments. This approach can prevent simulation sessions from becoming stand-alone events [35], and establishing simulation rooms when constructing new hospitals should be considered. These rooms should preferably be located close to departments where various specialties work together and team training can take place. New wards, emergency rooms, operating theatres and delivery wards can also be designed to facilitate ISS, e.g. in the form of video-recording equipment and rooms nearby for debriefing.

\section{Sharing facilities and simulation equipment (Table 2, point 14-17)}

Cooperation between departments can enable better use of rooms and simulation equipment. Further coordination between local simulation in hospital departments and simulation centres will help to avoid the purchase of equipment that will be underutilised and contribute to relevant access to technicians. Department-based simulations could be supported by simulation centres to ensure that simulation programmes are adequately developed and standardised. Further this might help to guarantee that simulation instructors are sufficiently trained, in addition to encouraging and coordinating simulation research $[45,46]$. Research on inter-professional postgraduate simulation shows that simulation conducted in close proximity to the clinical setting has a positive impact and that the departments involved gain useful organisational information for improving care [20, 21, 23, 27, 28, 37, 58, $63,64]$, which are arguments for incorporating simulation facilities in new hospitals.

Simulation-based activities involving high-tech simulation for technically advanced clinical procedures are most often centralised in simulation centres due to the advanced level of the simulators and the requirements they pose on their users [65].

Although several studies show that successful ISS can take place with at a minimal cost compared to simulation centres [19, 29, 66-68], ISS can require extra space for clinical activities, which may mean increased costs.

\section{Discussion of setting, context and physical fidelity}

To some extent, this article uses the term setting synonymously with context or physical surroundings. However, context can be expanded to also include more than the physical context, i.e. the semantic and commitment context [15]. Semantic context reflects how well the 
context contributes to the learning task while commitment context reflects motivation and responsibility [15]. One argument in favour of ISS is the contextual similarity to the context of working. The rooms and the equipment, for example are "real", even though they are used for simulation purposes $[19,47,69]$.

Many argue for learning in context $[2,11]$ based on various studies $[11,13,14]$. Some medical educators question whether fidelity plays a prominent role in the context [15-17]. The notion behind the idea of fidelity is that the more closely the simulation resembles the context of practice, the better the learning. However, the comparison studies on settings for simulation described in this article [20, 23, 27-29] indicate that the physical context or physical fidelity of the simulation setting, such as OSS or ISS, is not the most important aspect for individual and team learning, indicating that the semantic and motivational context can be more important.

\section{Perspectives on future research}

In general, we found that choice of setting does not seem to influence individual and team learning; however, future research would benefit from collaboration between medical education researchers and practical organisers of simulations as more research is necessary to better understand what additional aspects of simulation are fundamental for learning.

Carrying out simulation is costly and SBME is also expected to increase substantially in the coming years. Specific areas that would benefit from future research include the implementation of simulation [70] and the interplay between and the role of local organisers of simulations and of simulation centres. Research would profit greatly by encouraging collaboration between practical organisers of simulations and medical education researchers. Based on our studies the use of cross training was ill-advised [27, 28], but more research is warranted that involves groups beyond the postgraduate multiprofessional teams we examined.

The term sociological fidelity has recently been introduced in the field of simulation and expresses the interactions between learners in order to create authenticity with high levels of social realism [35, 42]. Additional research on sociological fidelity may be relevant as factors related to the interaction between simulation participants appear to be of more importance than the simulation's physical setting. The current understanding of fidelity as physical and psychological fidelity is under debate $[16,17,52,71]$ and may not be adequate enough to explain the learning-relevant processes in inter-professional simulation. Discussing the importance of social practice, hierarchy, power relations and other factors affecting inter-professional teamwork is rather new in the simulation literature [35,
$42,52,72]$ and exploring concepts like sociological fidelity may prove useful in future research on simulation.

Situativity theory [13] argues that knowledge, thinking and learning are situated in experience [11, 13, 73]. However, results from the above-mentioned comparison studies [20, 23, 27-29] on different simulation settings seem to show that some of the physical aspects of the simulation setting play a minor role compared to other factors. This assumption appears to be partly inconsistent with situated learning theory, which states that increased fidelity leads to improved learning [13], but does not consistently appear to be the case for physical fidelity. Future research could help to more sharply define what influences the learning context.

Participants in postgraduate simulation thought that participating in authentic teams in their own roles as healthcare professionals was important $[27,28]$; however, we need to know if this perception affects learning and clinical performance. This perception stands in contrast to the premise behind cross training, which is recommended in the simulation literature [3, 74]. Cross training is defined as "an instructional strategy in which each team member is trained in the duties of his or her teammates" [75]. It is argued that if all team members have a shared understanding of other people's roles, the risk of making errors decreases. Although there are empirical studies that address cross training, they only comprise small teams in an experimental laboratory setting and, to our knowledge, no medical studies have been undertaken that involve postgraduate multi-professional medical teams [74-76].

\section{Conclusions}

Based on the current limited research [20, 23, 27-29], we conclude that the choice of physical setting for simulations does not seem to influence individual and team learning. Department-based local simulation, such as OSS in-house and especially ISS, leads to gains in organisational learning, and unannounced ISS appears to provide more organisational learning than announced ISS $[27,28]$. The overall objectives and aim of a simulation and factors such as feasibility can help determine which simulation setting to choose. Studies on postgraduate inter-professional training show that local training, such as announced and unannounced ISS or OSS in-house, offers various advantages, e.g. locally run courses benefit local organisational learning, reduce costs and increase the accessibility of training for professional staff $[37,58,63,64]$. Some of the potential disadvantages of holding courses locally can be organisational problems and poor quality content due to badly organised simulations and a lack of qualified simulation instructors. These disadvantages need to be specifically addressed, and explicit collaboration and 
coordination between the organisers of local simulation and simulation centres can be recommended and may help avoid some of these issues. The advantages and disadvantages of announced and unannounced ISS are poorly explored in the literature, but some individuals who have participated in unannounced ISS describe it as intimidating, and unpleasant $[22,25]$.

\section{Abbreviation}

ISS: In situ simulation; OSS: Off-site simulation; SBME: Simulation-based medical education

\section{Acknowledgments \\ Not applicable.}

\section{Funding}

Non-profit foundations, including the Danish Regions Development and Research Foundation, the Laerdal Foundation for Acute Medicine, and the Aase and Ejnar Danielsen Foundation funded the research on the role of simulation setting and fidelity in simulation $[27,28]$. None of the funding providers contributed to the content or writing of this article.

\section{Availability of data and materials}

The data supporting the conclusions of this article are included within the article. Corresponding author may be contacted to forward requests for data sharing from own original publications $[27,28]$

\section{Authors' contributions}

$J$ LS has a research interest in inter-professional simulation and SBME and came up with the idea for this article in the final phase of completing her doctoral dissertation at Maastricht University, which was about designing SBME and the role of simulation setting and physical fidelity. She has been principal investigator on several research projects involving choice of simulation setting that were supervised by CVDV and BO. JLS wrote the first draft in discussion with CVDV and BO but the subsequent versions were written in discussion with all authors DO, VL, LK and PD. All authors read and approved the final manuscript.

\section{Competing interests}

The authors declare that they have no competing interest. The authors alone are responsible for the content and writing of this article.

\section{Consent to publish}

Not applicable.

\section{Ethics approval and consent to participate}

References 27 and 28 got approval from the Regional Ethics Committee (protocol number H-2-2012-155) and the Danish Data Protection Agency (Number 2007-58-0015).

\section{Author details}

'Juliane Marie Centre for Children, Women and Reproduction, Rigshospitalet, University of Copenhagen, 2100 Copenhagen, Denmark. ${ }^{2}$ Copenhagen Academy for Medical Education and Simulation, Herlev Hospital, Capita Region of Denmark and University of Copenhagen, 2730 Herlev, Denmark ${ }^{3}$ Department of Innovation in Medical Education, University of Ottawa, Ottawa, Canada. ${ }^{4}$ University of Ottawa Skills and Simulation Centre, The Ottawa Hospital, \& University of Ottawa, K1Y 4E9 Ottawa, Canada.

${ }^{5}$ Copenhagen Academy for Medical Education and Simulation, Rigshospitalet, Capital Region of Denmark and University of Copenhagen, 2100 Copenhagen, Denmark. ${ }^{6}$ Department of Educational Development and Research, Faculty of Health, Medicine and Life Sciences, Maastricht University, 6200 Maastricht, Netherlands.

Received: 18 June 2016 Accepted: 5 December 2016 Published online: 21 January 2017

\section{References}

1. Issenberg SB, McGaghie WC, Petrusa ER, Lee GD, Scalese RJ. Features and uses of high-fidelity medical simulations that lead to effective learning: a BEME systematic review. Med Teach. 2005:27:10-28.

2. McGaghie WC, Issenberg SB, Petrusa ER, Scalese RJ. A critical review of simulation-based medical education research: 2003-2009. Med Educ. 2010; 44:50-63.

3. Motola I, Devine LA, Chung HS, Sullivan JE, Issenberg SB. Simulation in healthcare education: a best evidence practical guide. AMEE Guide No. 82 Med Teach. 2013;35:e1511-30.

4. McGaghie WC, Issenberg SB, Barsuk JH, Wayne DB. A critical review of simulation-based mastery learning with translational outcomes. Med Educ. 2014:48:375-85.

5. Cook DA, Hatala R, Brydges R, Zendejas B, Szostek JH, Wang AT, Erwin PJ, Hamstra SJ. Technology-enhanced simulation for health professions education: a systematic review and meta-analysis. JAMA. 2011;306:978-88.

6. Cook DA, Hamstra SJ, Brydges R, Zendejas B, Szostek JH, Wang AT, Erwin PJ, Hatala R. Comparative effectiveness of instructional design features in simulation-based education: systematic review and meta-analysis. Med Teach. 2013;35:e867-98.

7. Brydges R, Hatala R, Zendejas B, Erwin PJ, Cook DA. Linking simulationbased educational assessments and patient-related outcomes: a systematic review and meta-analysis. Acad Med. 2015;90:246-56.

8. Gaba DM. The future vision of simulation in healthcare. Simul Healthc. 2007;2:126-35.

9. Salas E, Paige JT, Rosen MA. Creating new realities in healthcare: the status of simulation-based training as a patient safety improvement strategy. BMJ Qual Saf. 2013:22:449-52

10. Sollid SJ, Dieckman P, Aase K, Soreide E, Ringsted C, Ostergaard D. Five Topics Health Care Simulation Can Address to Improve Patient Safety: Results From a Consensus Process. J Patient Saf. 2016 Mar 28. [Epub ahead of print]

11. Teunissen PW, Wilkinson TJ. Learning and teaching in workplaces. In: Dornan T, Mann K, Scherpbier A, Spencer J, editors. Medical Education: Theory and Practice. Edinburgh, London, New York, Oxford, Philadelphia, St Louis, Sydney, Toronto: Churchill Livingstone Elsevier; 2011. p. 193-209.

12. Glossary. In: Dornan T, Mann K, Scherpbier A, Spencer J, editors. Medical Education: Theory and Practice. Edinburgh, London, New York, Oxford, Philadelphia, St Louis, Sydney, Toronto: Churchill Livingstone Elsevier; 2011. p. 339-49

13. Durning SJ, Artino AR. Situativity theory: a perspective on how participants and the environment can interact: AMEE Guide no. 52. Med Teach. 2011;33: 188-99.

14. Godden DR, Baddeley AD. Context-dependent memory in two natural environments: on land and underwater. Br J Psychol. 1975;66:325-31.

15. Koens F, Mann KV, Custers EJ, Ten Cate OT. Analysing the concept of context in medical education. Med Educ. 2005;39:1243-9.

16. Grierson LE. Information processing, specificity of practice, and the transfer of learning: considerations for reconsidering fidelity. Adv Health Sci Educ Theory Pract. 2014;19:281-9.

17. Norman G, Dore K, Grierson L. The minimal relationship between simulation fidelity and transfer of learning. Med Educ. 2012;46:636-47.

18. Rehmann A, Mitman RD, Reynolds MC. A handbook of flight simulation fidelity requirements for human factors research. Atlantic City Airport, NJ 08405: U.S. Department ofTransportation Federal Aviation Administration; 1995.

19. Rosen MA, Hunt EA, Pronovost PJ, Federowicz MA, Weaver SJ. In situ simulation in continuing education for the health care professions: a systematic review. J Contin Educ Health Prof. 2012;32:243-54.

20. Ellis D, Crofts JF, Hunt LP, Read M, Fox R, James M. Hospital, simulation center, and teamwork training for eclampsia management: a randomized controlled trial. Obstet Gynecol. 2008;111:723-31.

21. Sørensen JL, Løkkegaard E, Johansen M, Ringsted C, Kreiner S, McAleer S. The implementation and evaluation of a mandatory multi-professional obstetric skills training program. Acta Obstet Gynecol Scand. 2009;88:1107-17.

22. Sørensen JL, Lottrup $P$, van der Vleuten $C$, Andersen KS, Simonsen $M$, Emmersen P, Rosthoj S, Ottesen B. Unannounced in situ simulation of obstetric emergencies: staff perceptions and organisational impact. Postgrad Med J. 2014;90:622-9.

23. Crofts JF, Ellis D, Draycott TJ, Winter C, Hunt LP, Akande VA. Change in knowledge of midwives and obstetricians following obstetric emergency training: a randomised controlled trial of local hospital, simulation centre and teamwork training. BJOG. 2007;114:1534-41. 
24. Riley W, Davis S, Miller KM, Hansen H, Sweet RM. Detecting breaches in defensive barriers using in situ simulation for obstetric emergencies. Qual Saf Health Care. 2010;19 Suppl 3:153-6.

25. Anderson ER, Black $R$, Brocklehurst $P$. Acute obstetric emergency drill in England and Wales: a survey of practice. BJOG. 2005;112:372-5.

26. Spurr J, Gatward J, Joshi N, Carley SD. Top $10(+1)$ tips to get started with in situ simulation in emergency and critical care departments. Emerg Med J. 2016;33:514-6.

27. Sørensen JL, van der Vleuten C, Rosthoj S, Oestergaard D, Leblanc V, Johansen M, Ekelund K, Starkopf L, Lindschou J, Gluud C, Weikop P, Ottesen B. Simulation-based multiprofessional obstetric anaesthesia training conducted in situ versus off-site leads to similar individual and team outcomes: results from a randomised educational trial. BMJ Open. 2015;5: e008344. doi:10.1136/bmjopen-2015-008344.

28. Sørensen JL, Navne LE, Martin HM, Ottesen B, Albrechtsen CK, Pedersen BW, Kjaergaard $\mathrm{H}$, van der Vleuten $\mathrm{C}$. Clarifying the learning experiences of healthcare professionals with in situ versus off-site simulation-based medical education: a qualitative study. BMJ Open. 2015:5:e008345. doi:10.1136/ bmjopen-2015-008345.

29. Couto TB, Kerrey BT, Taylor RG, FitzGerald M, Geis GL. Teamwork skills in actual, in situ, and in-center pediatric emergencies: performance levels across settings and perceptions of comparative educational impact. Simul Healthc. 2015;10:76-84.

30. Thomas PA. Goals and objectives. In: Kern DE, Thomas PA, Howard DM, Bass EB, editors. Curriculum development for medical education a six step approach. 2nd ed. London: The John Hopkins University Press; 2009. p. 43-51.

31. Bradley P, Bligh J. Clinical skills centres: where are we going? Med Educ. 2005;39:649-50.

32. Caro PW. Aircraft simulators and pilot training. Hum Factors. 1973;15:502-9.

33. Carayon P, Schoofs HA, Karsh BT, Gurses AP, Alvarado CJ, Smith M, et al. Work system design for patient safety: the SEIPS model. Qual Saf Health Care. 2006;15 Suppl 1:150-8.

34. Bender GJ. In situ simulation for systems testing in newly constructed perinatal facilities. Semin Perinatol. 2011;35:80-3.

35. Boet S, Bould MD, Layat BC, Reeves S. Twelve tips for a successful interprofessional team-based high-fidelity simulation education session. Med Teach. 2014;36:853-7.

36. Larsen DP, Butler AC, Roediger III HL. Test-enhanced learning in medical education. Med Educ. 2008:42:959-66.

37. Draycott TJ, Collins KJ, Crofts JF, Siassakos D, Winter C, Weiner CP, et al. Myths and realities of training in obstetric emergencies. Best Pract Res Clin Obstet Gynaecol. 2015;29:1067-76.

38. Sørensen JL, Thellensen L, Strandbygaard J, Svendsen KD, Christensen KB, Johansen M, Langhoff-Roos P, Ekelund K, Ottesen B, van der Vleuten C. Development of a knowledge test for multi-disciplinary emergency training: a review and an example. Acta Anaesthesiol Scand. 2015;59:123-33.

39. Holmboe ES, Sherbino J, Long DM, Swing SR, Frank JR. The role of assessment in competency-based medical education. Med Teach. 2010;32:676-82

40. Fokkema JP, Teunissen PW, Westerman M, van der Lee N, van der Vleuten CP, Scherbier AJ, Dorr PJ, Scheele F. Exploration of perceived effects of innovations in postgraduate medical education. Med Educ. 2013;47:271-81.

41. Patterson MD, Geis GL, Falcone RA, Lemaster T, Wears RL. In situ simulation: detection of safety threats and teamwork training in a high risk emergency department. BMJ Qual Saf. 2013:22:468-77.

42. Sharma S, Boet $S$, Kitto $S$, Reeves $S$. Interprofessional simulated learning: the need for 'sociological fidelity'. J Interprof Care. 2011;25:81-3.

43. Bullough AS, Wagner S, Boland T, Waters TP, Kim K, Adams W. Obstetric team simulation program challenges. J Clin Anesth. 2016;35:564-70.

44. Savoldelli GL, Naik VN, Hamstra SJ, Morgan PJ. Barriers to use of simulationbased education. Can J Anaesth. 2005:52:944-50.

45. Dieckmann P, Molin FS, Lippert A, Ostergaard D. The art and science of debriefing in simulation: Ideal and practice. Med Teach. 2009;31:e287-94

46. Møller TP, Østergaard D, Lippert A. Facts and fiction - Training in centres or in situ. Trends Anaesth Crit Care. 2012;2:174-9.

47. Walker ST, Sevdalis N, McKay A, Lambden S, Gautama S, Aggarwal R, Vincent C. Unannounced in situ simulations: integrating training and clinical practice. BMJ Qual Saf. 2013;22:453-8.

48 Vincent C. Unannounced in situ simulations: integrating training and clinical practice. BMJ Qual Saf. 2013;22:453-8.

49. Stocker M, Burmester M, Allen M. Optimisation of simulated team training through the application of learning theories: a debate for a conceptual framework. BMC Med Educ. 2014;14:69.
50. Kobayashi L, Dunbar-Viveiros JA, Sheahan BA, Rezendes MH, Devine J, Cooper MR, Martin PB, Jay GD. In situ simulation comparing in-hospital first responder sudden cardiac arrest resuscitation using semiautomated defibrillators and automated external defibrillators. Simul Healthc. 2010;5:82-90.

51. Manser T, Dieckmann P, Wehner T, Rallf M. Comparison of anaesthetists' activity patterns in the operating room and during simulation. Ergonomics. 2007;50:246-60

52. Dieckmann P, Gaba D, Rall M. Deepening the theoretical foundations of patient simulation as social practice. Simul Healthc. 2007;2:183-93.

53. Wheeler DS, Geis G, Mack EH, Lemaster T, Patterson MD. High-reliability emergency response teams in the hospital: improving quality and safety using in situ simulation training. BMJ Qual Saf. 2013;22:507-14.

54. Geis GL, Pio B, Pendergrass TL, Moyer MR, Patterson MD. Simulation to assess the safety of new healthcare teams and new facilities. Simul Healthc. 2011;6:125-33.

55. Preston P, Lopez C, Corbett N. How to integrate findings from simulation exercises to improve obstetrics care in the institution. Semin Perinatol. 2011;35:84-8.

56. Kobayashi L, Shapiro MJ, Sucov A, Woolard R, Boss III RM, Dunbar J, et al. Portable advanced medical simulation for new emergency department testing and orientation. Acad Emerg Med. 2006;13:691-5.

57. Kobayashi L, Parchuri R, Gardiner FG, Paolucci GA, Tomaselli NM, Al-Rasheed RS, et al. Use of in situ simulation and human factors engineering to assess and improve emergency department clinical systems for timely telemetrybased detection of life-threatening arrhythmias. BMJ Qual Saf. 2013;22:72-83.

58. Cornthwaite K, Edwards S, Siassakos D. Reducing risk in maternity by optimising teamwork and leadership: an evidence-based approach to save mothers and babies. Best Pract Res Clin Obstet Gynaecol. 2013;27:571-81.

59. Raemer DB. Ignaz semmelweis redux? Simul Healthc. 2014;9:153-5.

60 Moss C, Walsh K, Mitchell J. Plotting care: a modelling technique for visioning nursing practice in current and future contexts. Contemp Nurse. 2010;35:188-201.

61. Ecoff $L$, Thomason T. Moving into a new hospital: strategies for success. J Nurs Adm. 2009;39:499-503.

62. Nordquist J, Sundberg K, Laing A. Aligning physical learning spaces with the curriculum: AMEE Guide No. 107. Med Teach. 2016:1-14

63. Siassakos D, Crofts JF, Winter C, Weiner CP, Draycott TJ. The active components of effective training in obstetric emergencies. BJOG. 2009;116:1028-32.

64. Bergh AM, Baloyi S, Pattinson RC. What is the impact of multi-professional emergency obstetric and neonatal care training? Best Pract Res Clin Obstet Gynaecol. 2015;29:1028-43.

65. Konge L, Ringsted C, Bjerrum F, Tolsgaard MG, Bitsch M, Sorensen JL, et al. The simulation centre at rigshospitalet, Copenhagen, Denmark. J Surg Educ. 2015;72:362-5

66. Calhoun AW, Boone MC, Peterson EB, Boland KA, Montgomery VL. Integrated in-situ simulation using redirected faculty educational time to minimize costs: a feasibility study. Simul Healthc. 2011;6:337-44.

67. van Schaik SM, Plant J, Diane S, Tsang L, O'Sullivan P. Interprofessional team training in pediatric resuscitation: a low-cost, in situ simulation program that enhances self-efficacy among participants. Clin Pediatr. 2011:50:807-15.

68. Edler AA, Chen M, Honkanen A, Hackel A, Golianu B. Affordable simulation for small-scale training and assessment. Simul Healthc. 2010;5:112-5.

69. Patterson MD, Geis GL, Lemaster T, Wears RL. Impact of multidisciplinary simulation-based training on patient safety in a paediatric emergency department. BMJ Qual Saf. 2013;22:383-93.

70. Bergh AM, Allanson E, Pattinson RC. What is needed for taking emergency obstetric and neonatal programmes to scale? Best Pract Res Clin Obstet Gynaecol. 2015;29:1017-27.

71. Hamstra SJ, Brydges R, Hatala R, Zendejas B, Cook DA. Reconsidering fidelity in simulation-based training. Acad Med. 2014;89:387-92.

72. Sydor DT, Bould MD, Naik VN, Burjorjee J, Arzola C, Hayter M, et al. Challenging authority during a life-threatening crisis: the effect of operating theatre hierarchy. Br J Anaesth. 2013;110:463-71.

73. Teteris E, Fraser K, Wright B, McLaughlin K. Does training learners on simulators benefit real patients? Adv Health Sci Educ Theory Pract. 2012;17:137-44.

74. Wilson KA, Burke CS, Priest HA, Salas E. Promoting health care safety through training high reliability teams. Qual Saf Health Care. 2005;14:303-9.

75. Marks MA, Sabella MJ, Burke CS, Zaccaro SJ. The impact of cross-training on team effectiveness. J Appl Psychol. 2002;87:3-13.

76. Volpe CE, Cannon-Bowers JA, Salas E, Spector PE. The impact of cross-training on team functioning: an empirical investigation. Hum Factors. 1996;38:87-100. 